Anoshina Yulia Fyodorovna, Doctor of Economics, Professor of the Department of Economics, Russian state University of justice (69, Novocheremushkinskaya str., Moscow, 117418, Russian Federation). E-mail: jfano@mail.ru

Naumkina Tatyana Vasilyevna, Candidate of Law, Associate Professor of Economics, Russian state University of justice (69, Novocheremushkinskaya str., Moscow, 117418, Russian Federation).

E-mail: naumkinantv@gmail.com

\title{
STATE REGULATION OF THE FISHERIES COMPLEX OF THE RUSSIAN FEDERATION IN MODERN CONDITIONS \\ Abstract
}

Achieving the goals and objectives aimed at accelerated development of the Russian Federation's fisheries sector is possible only by creating mechanisms of state regulation that increase the investment attractiveness of the fishing industry, updating and modernizing fixed assets and infrastructure, including the construction of a modern fishing fleet and high-tech fish processing enterprises, increasing the depth of processing of fish products and increasing the share of these products in export deliveries. The article analyzes the regulation of the country's fisheries sector. The problems of legislative support for the development of the fishing industry are identified. It is precisely the improvement of the mechanism of state regulation in this sector of the Russian economy that is becoming an objective condition and need for the practice of its modern market economy. The current situation of the country's fishing fleet is assessed.

Keywords: politics, economy, industry, state program, state regulation, fishing industry, fisheries complex, fisheries activities, water biological resources.

\section{References}

1. Anoshina YU.F., Kostina O.V. Tovarno-sbytovaya politika predpriyatij APK kak effektivnyj instrument v sisteme prodovol'stvennogo obespecheniya regiona: monografiya. M.: Sputnik+, 2009. 154 p.

2. Anoshina YU.F., Sapegina M.V. Razvitie prodovol'stvennogo rynka: ocenka i regulirovanie (monografiya). M.: Sputnik+, 2007. $178 \mathrm{p}$.

3. Ostroumova I.N., SHumilina A.K., Koz'mina A.V. Problema kachestva rybnoj muki i drugih komponentov v kormah ryb // Aktual'nye problemy akvakul'tury v sovremennyj period: Materialy Mezhdunarodnoj nauchnoj konferencii, 28 sentyabrya - 2 oktyabrya 2015 g., g. Rostov-na-Donu, FGBNU «AzNIIRH».- Izd-vo: FGBNU «AzNIIRH», 2015. P. 127 - 129.

\section{ТРАНСФОРМАЦИЯ МЕХАНИЗМА ГОСУДАРСТВЕННОЙ ПОДДЕРЖКИ АПК С ИСПОЛЬЗОВАНИЕМ ИНСТРУМЕНТАРИЯ ПРОЕКТНОГО МЕНЕДЖМЕНТА}

\author{
Бобровнич \\ Александр \\ Александрович \\ Горбачева \\ Анна \\ Александровна
}

\author{
преподаватель, Южно-Российский институт управления - филиал \\ Российской академии народного хозяйства и государственной \\ службы при Президенте РФ (344002, Россия, г. Ростов-на-Дону, \\ ул. Пушкинская, 70/54). E-mail: bobrik161@mail.ru \\ кандидат экономических наук, доцент кафедры экономической теории, \\ Московский государственный институт международных отношений \\ (Университет) Министерства иностранных дел Российской Федерации \\ (119454, Россия, г. Москва, пр. Вернадского, 76). \\ E-mail: annagorbacheva.mgimo@gmail.com
}

\section{Аннотация}

В статье проводится анализ существующей системы государственной поддержки АПК Российской Федерации, исследуются тенденции ее развития и предлагается трансформировать механизм поддержки хозяйствующих субъектов посредством формирования комплексной системы создания и реализации приоритетных проектов в сфере АПК с участием гибких интеграционных объединений. Предлагаемый подход может стать основой развития приоритетных направлений, объединив вокруг себя на взаимовыгодных всех заинтересованных экономических субъектов.

Ключевые слова: агропромышленный комплекс, государственное регулирование экономики, государственная поддержка АПК, государственная программа, национальный проект, приоритетный проект, проектное управления, проектная деятельность, субсидия, хозяйствующий субъект, гибкое интеграционное объединение.

Государственное регулирование агропромышленного комплекса представляет собой одно из стратегически важных направлений государственной экономической политики в целом. В современных условиях дисбаланса экономики и влияния глобализации абсолютное саморегулирование деятельности экономических субъектов невозможно и может привести к серьезным затруднениям развития экономики страны. Поэтому государство использует соответствующие инструменты 
и методы экономического прогнозирования, программирования и регулирования, способствуя тем самым предотвращению негативного влияния политических, природных и иных факторов.

В Российской Федерации государственная поддержка различных отраслей (в том числе и АПК) строится на основе программного механизма и реализуется через государственные программы, которые определяют цели, задачи и основные направления развития отрасли. Как отмечает А.В. Ильичев [1, с. 19], формирование программ связано с проблемными позициями в части определения цели и задач деятельности, определение и оценки ключевых показателей эффективности, осуществления мероприятий и управления программой по прогнозным результатам. Поэтому, по мнению Ю.Н. Шедько[2, с. 24], программно-целевой метод способствует недопущению чрезмерной дифференциации показателей и уровня развития регионов. В.И. Самарухи, Т.В. Сорокиной отмечают [3, c. 25], что программы создают условия для обеспечения пространственной поляризации регионов.

В 2017 г. Минсельхоз России реформировал систему господдержки АПК, изменив механизм субсидирования кредитов и введя субсидирование процентной ставки сразу при получении кредита в банке, сохранив администрирование крупных направлений субсидирования АПК и передав распределение остальных направлений на усмотрение регионов. Соответственно, сформирована «единая субсидия», объединившая 26 различных субсидий, и изменены правила отбора проектов для возмещения части понесенных капитальных затрат. Каждый субъект Российской Федерации получает единую сумму средств для ее распределения на основе региональной специфики и имеющихся потребностей.

Проводимые изменения были неоднозначно приняты сельхозпроизводителями. В качестве ключевого вопроса в отношении господдержки эксперты отмечают наличие диспропорции в распределении субсидий и недостаточно выделяемый объем для фермеров и мелких производителей. В среднем на них приходится всего 20\% средств. При этом 50\% всей производимой сельхозпродукции ${ }^{1}$ производится именно фермерами и мелкими производителями. В целом в 2018 г. Минсельхозом России одобрено 3035 заявок (из 3114 поступивших) на получение льготных краткосрочных кредитов от 2773 заемщиков - малых форм хозяйствования на общую сумму 25,16 млрд руб. и сумму субсидий 1,59 млрд руб. При этом процент малых предприятий составил порядка 50\% от общего числа получателей. ${ }^{2}$

В этой связи, по нашему мнению, вопрос заключается не в реализации отдельно взятых видов господдержки, а в принятии комплексных мер поддержки в зависимости от осуществляемой хозяйственной деятельности. При этом, как отмечает А.Г. Гранберг, организация и механизмы реализации госпрограмм требуют значительного совершенствования, сокращения реализуемых госпрограмм и формирования их мероприятий с учетом интересов и потребностей организаций в сфере АПК [4, с. 311]. Тем более, как показывает анализ динамики достижения значений показателей, более половины показателей ежегодно не достигается.

В современных условиях развития общества и экономики трансформация инструментов господдержки должна быть направлена на обеспечение прозрачности принимаемых решений и вовлечение всех заинтересованных участников. В связи с чем в госсекторе активно начался процесс внедрения технологий проектного управления для достижения общественно значимых результатов. При этом ключевые отличия проектной от текущей (операционной) деятельности заключаются в ориентации на конкретный результат, в четкие сроки и определенный объем финансовых и трудовых ресурсов. ${ }^{3}$ Именно положительный опыт проектного управления позволил ряду зарубежных стран добиться ключевых результатов в развитии конкретных отраслей или реализации проектов (Германия, Франция, Австралия, Великобритании, Японии, США) 4 .

\footnotetext{
1 B распределении субсидий аграриям справедливости нет [Электронный ресурс]. Режим доступа: URL: http://kvedomosti.ru/news/kommentarij-v-raspredelenii-subsidij-agrariYam-spravedlivosti-net.html (дата обращения 01.12.2019).

2 Официальный сайт Министерства сельского хозяйства Российской Федерации [Электронный ресурс]. Режим доступа: URL: http://mcx.ru/ (дата обращения 10.01.2020); Малые формы хозяйствования получили льготных краткосрочных кредитов в 2,2 раза больше [Электронный ресурс]. Режим доступа: URL: https://www.zol.ru/n/2ba94 (дата обращения 01.12.2019); Гранты сокращают, освоение льготных кредитов плачевно! [Электронный ресурс]. Режим доступа: URL: http://kvedomosti.ru/news/kommentarijgranty-sokrashhayut-osvoenie-lgotnyx-kreditov-plachevno.html (дата обращения 03.12.2019).

3 Agile-методологии внедряются в работу госсектора. [Электронный ресурс]. Режим доступа: URL: http://ac.gov.ru/events/08816.html (дата обращения 18.12.2019).

${ }^{4}$ Шестопалов П.Л. Управление проектами в органах власти. [Электронный ресурс]. Режим доступа: URL: http://pmolimp.ru/2018/news / (дата обращения 18.12.2019).
} 
В 2011 г. Правительство Великобритании в качестве ключевых принципов внедрения проектной деятельности и осуществления господдержки определило наличие высокорискованных и комплексных инфраструктурных проектов, формирование высокопрофессиональной команды и оптимизацию процесса проектной деятельности. Это позволило сформировать портфель из 200 приоритетных проектов с бюджетом в 500 млрд фунтов стерлингов. В Японии с 2005 года реализация национальных программ сопровождалась внедрением соответствующей методологии государственного проектирования и реализации проектов по развитию инфраструктуры и бизнеса Р2М и КРМ. Правительство США осуществляет управление проектами на основе специальной версии стандарта PMBOK Government Extension (Свод знаний по управлению проектами в государственных органах), описывающей ключевые процессы управления проектами. Интересно, что в современных условиях изменение подходов к управлению и оказанию господдержки на основе проектной деятельности продолжает развиваться в рамках реализации межгосударственных проектов и разработки международных программ сертификации менеджеров проектов [5, с. 49].

Разработка национальных программ и проектов является одним из этапов внедрения инструментов проектного управления в госсектор Российской Федерации.

Анализ существующего механизма управления и господдержки в рамках госпрограмм свидетельствует о постепенной трансформации управленческих подходов и внедрении в стратегическое управление инструментов проектного управления

Стоит отметить, что метод управления проектами (Project Management), в отличие от упомянутого выше программно-целевого метода, ориентирован именно на достижение цели и повышение эффективности. Кроме того, данный метод позволяет разрабатывать стандарты проектного управления. В этой связи процесс достижения поставленных задач детализируется множеством параметров (в т.ч. ресурсных и временных). Однако основное отличие между указанными методами заключается в выборе объекта управления, периоде планирования, снижении риска неопределенности и иных управленческих рисков. Тем не менее, внедрение сильных сторон проектного управления в программно-целевой метод госпрограмм и осуществление господдержки призвано повысить качество целеполагания и улучшить управляемость госпрограмм и проектов на ключевых этапах:

- постановки целей и задач;

- этапе реализации.

Однако в современных условиях процессы стратегического, портфельного, проектного и бюджетного планирования не синхронизированы между собой, а работа по проектам зачастую дублируется с текущей операционной деятельностью (рис. 1).

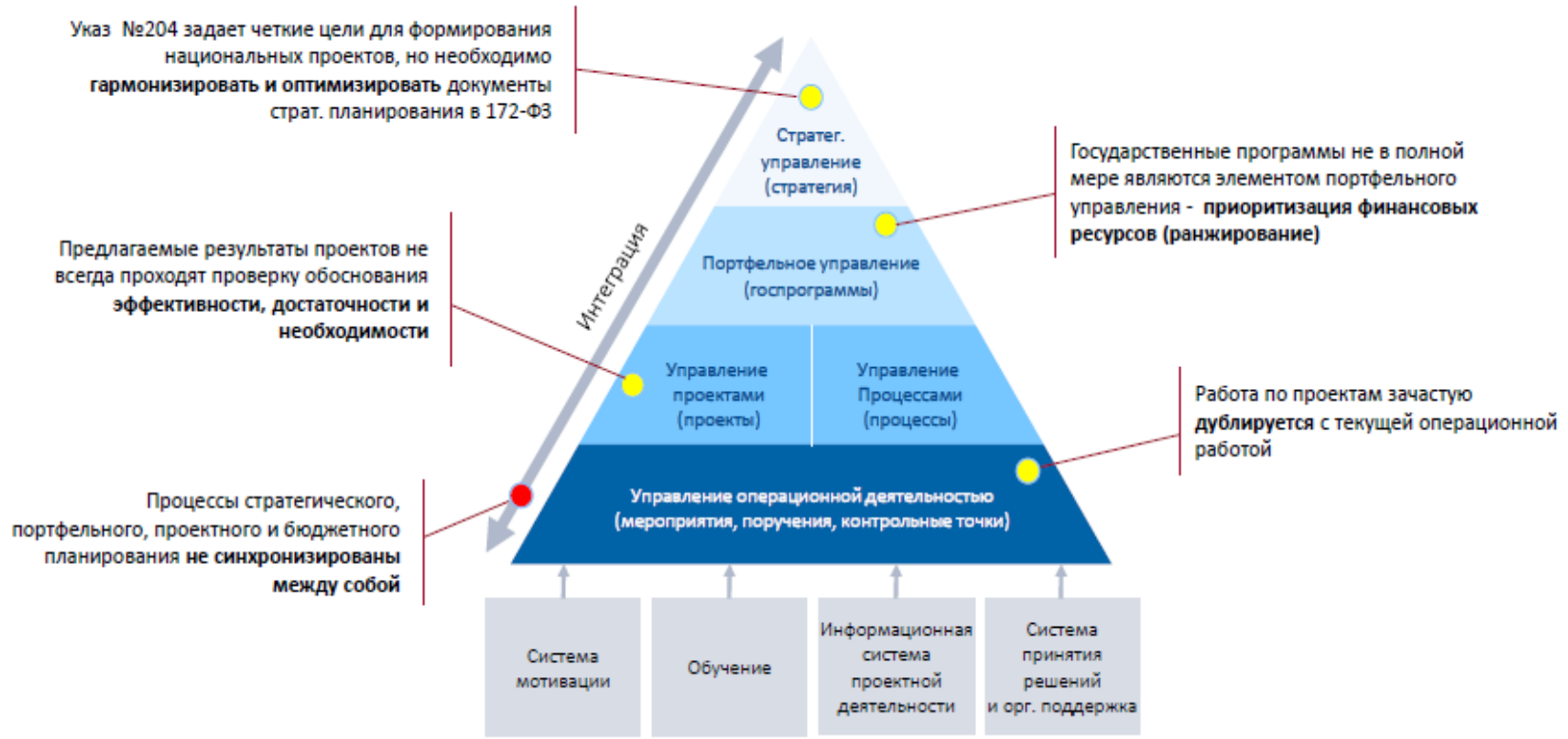

Рис. 1. Существующие проблемы внедрения проектной деятельности действующий механизм господдержки [6]

Авторами исследования предлагается трансформировать механизм поддержки хозяйствующих субъектов посредством формирования комплексного механизма создания и реализации приоритетных проектов в сфере АПК с участием гибких интеграционных объединений. Целесообразность их включения основывается на получении возможности участия в инициировании проектов, 
включении их в региональные, федеральные и национальные проекты, программы и госпрограммы, привлечении к их реализации различных субъектов хозяйственной деятельности вне зависимости от организационной формы.

Согласно результатам опроса глав крестьянских (фермерских) хозяйств в 2017-2018 годах в фермерском секторе отмечаются следующие проблемы: ${ }^{1}$

- сокращение спроса на продукцию одновременно с повышением стоимости ее производства (99\% респондентов);

- рост тарифов на ГСМ и услуги естественных монополий (также 99\% опрошенных);

- немногочисленность каналов сбыта фермерской продукции (95\% опрошенных);

- сокращение возможностей банковского кредитования (70\% опрошенных);

- низкая доступность аренды или приобретения земельных ресурсов;

- слабое развитие производственной кооперации (26\% респондентов).

Несмотря на то что в целом перспективы развития фермерского сектора сельского хозяйства Российской Федерации характеризуются как положительные, а также на тот факт, что объем сельскохозяйственного производства в этом секторе имеет тенденцию к увеличению, 85\% участников опроса планируют увеличивать выработку продукции; 69\% хозяйств планируют внедрять новые технологические разработки, закупать новую технику и запасные части ${ }^{2}$. При этом, как отмечается в разделе 2.1., в качестве положительных моментов стоит выделить увеличение объема сельскохозяйственного производства, животноводства, поголовья скота и птицы, лизинга (70\% опрошенных), обеспеченности семенными (посадочными) материалами (90\% опрошенных).

Соответственно, нами предлагается на уровне нормативных правовых актов Российской Федерации закрепить возможность оказания комплексной поддержки вертикально-горизонтальным интегрированным структурам, в рамках которых могут функционировать различные субъекты хозяйственной деятельности из различных отраслей и подотраслей АПК, институты, перерабатывающие производства и предприятия, специализирующиеся на реализации сельскохозяйственной продукции и сырья, а также сельского машиностроения. В данном случае значение приобретает конечная ценность производимого продукта, а также соответствие целей и задач развития такой структуры целям и задачам госпрограмм.

Целевая субсидия может доводиться гибким интеграционным объединениям на осуществление комплекса мероприятий АПК, в том числе на поддержку малоприбыльных или начинающих субъектов хозяйственной деятельности. Это позволит:

- перевести субъекты из разряда бесперспективных и убыточных в разряд прибыльных;

- создать условия для получения стабильного дохода производителями АПК продукции на основе понятных и планируемых тенденций развития;

- определить объем государственной ресурсной поддержки производителей.

Участие в механизме господдержки гибких интеграционных объединений позволит сфокусироваться на реализации приоритетных проектов, точечном использовании имеющихся ресурсов, трансформации форм их использования с учетом потребностей и интересов всех заинтересованных участников и уровней управления. Это будет способствовать оказанию финансовой поддержки не единичным структурам, а различным хозяйствующим субъектам, расположенным на относительно небольшом пространстве, в целях получения ими бюджетных средств для реализации определенных проектов. Тем самым, выстраивается комплексная предпринимательская среда на основе горизонтальной и вертикальной интеграции и формировании гибких интеграционных объединений.

Однако для осуществления эффективного взаимодействия участников агроэкономических отношений необходимо:

- представительство в партнерстве органов государственной власти, инновационных и инвестиционных центров;

- четкое определение проектов, общих целей и задач участников объединения;

- распределение между участниками расходов, рисков и полученных результатов от реализованных проектов;

\footnotetext{
1 Актуальные направления государственной поддержки АПК в РФ: Германо-Российский аграрнополитический диалог [Электронный ресурс]. Режим доступа: URL: www.agrardialog.ru (дата обращения 03.12.2019).

2 Deutsch-Russischer agrarpolitischer Dialog. Kooperationsprojekt des Bundesministeriums fur Ernahrung und Landwirtschaft der Bundesrepublik Deutschland Buro Moskau [Электронный ресурс]. Режим доступа: URL: www.agrardialog.ru (дата обращения 19.01.2020).
} 
- четкое разделение и специализация труда, а также формирование зависимости между выполняемым объемом задач и оплатой труда с учетом одновременного взаимовыгодного сотрудничества взаимозависимых субъектов в сфере АПК;

- учет интересов всех субъектов экономической деятельности вне зависимости от их организационно-правовой формы [7, с. 164];

- обеспечение системной рационализации управленческой деятельности на основе проектно-портфельной программы и проектного подхода.

Предлагаемый подход в рамках господдержки и осуществления проектной деятельности в сфере АПК может стать основой развития приоритетных направлений, объединив вокруг себя на взаимовыгодных отношениях организации-спутники (фермерские хозяйства, субъекты малого и среднего предпринимательства и т.д.).

Таким образом, развитие системы государственной поддержки АПК способно привести к повышению уровня эффективности использования имеющихся конкурентных преимуществ отрасли на всех уровнях страны в целом. Особенно важной становится задача максимально раскрыть имеющийся потенциал субъектов РФ, территорий, особенности их географического расположения.

В этой связи предлагаемая трансформация госпрограмм и включение в их состав интегрированных структур позволит, во-первых, оказывать государственную поддержку напрямую группе взаимосвязанных и взаимозависимых хозяйствующих субъектов в целях получения конечного продукта, имеющего коммерческий и социальный эффект для государства, общества, а также точечно достигать государственных целей и задач в сфере АПК.

Во-вторых, использование методологических принципов и методических подходов к концепции регулирования АПК на основе саморегулирования рынка и активного воздействия государственных органов создаст условия для стимулирования агропромышленной интеграции в сочетании с диверсификацией производства, финансовой поддержкой и мерами государственного регулирования процессов в АПК.

В-третьих, непосредственное участие интегрированных структур в разработке и реализации госпрограмм позволит повысить степень их заинтересованности не только в производстве конечного продукта, а также в реализации соответствующих мероприятий, которые способствуют достижению поставленных целей и задач. Тем самым, тесное сотрудничество бизнеса и государственных структур может стать новой эффективной основой развития АПК.

\section{Литература}

1. Ильичев A.B. Основы анализа эффективности и рисков целевых программ. Истоки, формализация, реализация. М.: Научный мир, 2009. 332 с.

2. Шедъко Ю.Н. Программно-целевой метод как инструмент повышения эффективности территориальных социоэкономических систем // Региональная экономика: теория и практика. 2010. № 44 (179). С. 24 - 30 .

3. Самаруха В.И., Сорокина Т.В. Применение программно-целевого метода в финансовом обеспечении бюджетного сектора региона // Известия Иркутской экономической академии. 2013. № 3. [Электронный ресурс]. Режим доступа: URL: http://eizvestia.isea.ru/ (дата обращения: 29.09.2018).

4. Гранберг А.Г. Основы региональной экономики. М.: ГУ-ВШЭ, 2001. 495 с.

5. Глазьев С.Ю., Батчиков С.А. Эффективность государственного управления. Под общей ред. С.Ю. Глазьева. М.: Фонд За экономическую грамотность, Российский экономический журнал, Изд-во ООО Консалтбанкир, 1998. 848 с.

6. Билев О. Проектный подход в государственном управлении: опыт, проблематика и перспективы. Официальный сайт центра проектного менеджмента РАНХиГС [Электронный ресурс]. Режим доступа: URL: https://pm.center/library/prezentatsii-i-doklady/ (дата обращения 15.12.2019).

7. Балашов А.П. Основы менеджмента. М.: Вузовский учебник, ИНФРА-М, 2020. 288 с.

Bobrovnich Alexander Alexandrovich, Lecturer, South-Russia Institute of Management - branch of Russian Presidential Academy of National Economy and Public Administration (70/54, Pushkinskaya St., Rostov-on-Don, 344002, Russian Federation). E-mail: bobrik161@mail.ru.

Gorbacheva Anna Alexandrovna, Ph. D. in Economics, Associate Professor, Moscow State Institute of International Relations (University) of the Ministry of Foreign Affairs of the Russian Federation (76, Vernadsky Ave., Moscow, 119454, Russian Federation). E-mail: annagorbacheva.mgimo@gmail.com 


\section{TRANSFORMATION OF THE MECHANISM OF STATE SUPPORT OF AGRICULTURE WITH THE USE OF THE PROJECT MANAGEMENT TOOL \\ Abstract}

The article analyzes the existing system of state support for the agro-industrial complex of the Russian Federation, explores its development trends and proposes to transform the support mechanism for business entities through the formation of an integrated system for creating and implementing priority projects in the agricultural sector with the participation of flexible integration associations. The proposed approach can become the basis for the development of priority areas, uniting around itself mutually beneficial all interested economic entities.

Keywords: agro-industrial complex, state regulation of the economy, state support for the agro-industrial complex, state program, national project, priority project, project management, project activity, subsidy, business entity, flexible integration association.

\section{References}

1. Il'ichev A.V. Osnovy analiza effektivnosti i riskov celevyh programm. Istoki, formalizaciya, realizaciya. M.: Nauchnyj mir, 2009. 332 p.

2. SHed'ko YU.N. Programmno-celevoj metod kak instrument povysheniya effektivnosti territorial'nyh socioekonomicheskih sistem // Regional'naya ekonomika: teoriya i praktika. 2010. № 44 (179). P. 24 - 30.

3. Samaruha V.I., Sorokina T.V. Primenenie programmno-celevogo metoda v finansovom obespechenii byudzhetnogo sektora regiona // Izvestiya Irkutskoj ekonomicheskoj akademii. 2013. №.3. [Elektronnyj resurs]. Rezhim dostupa: URL: http://eizvestia.isea.ru/ (data obrashcheniya: 29.09.2018).

4. Granberg A.G. Osnovy regional'noj ekonomiki. M.: GU-VSHE, 2001. 495 s.

5. Glaz'ev S.YU., Batchikov S.A. Effektivnost' gosudarstvennogo upravleniya. Pod obshchej red. S.YU. Glaz'eva. M.: Fond Za ekonomicheskuyu gramotnost', Rossijskij ekonomicheskij zhurnal, Izd-vo 000 Konsaltbankir, 1998. 848 p.

6. Bilev O. Proektnyj podhod v gosudarstvennom upravlenii: opyt, problematika i perspektivy. Oficial'nyj sajt centra proektnogo menedzhmenta RANHiGS [Elektronnyj resurs]. Rezhim dostupa: URL: https://pm.center/library/prezentatsii-i-doklady/ (data obrashcheniya 15.12.2019).

7. Balashov A.P. Osnovy menedzhmenta. M.: Vuzovskij uchebnik, INFRA-M, 2020. 288 p.

\section{ИНСТРУМЕНТЫ ЦИФРОВОЙ ЭКОНОМИКИ В КОНТЕКСТЕ ИХ ВЛИЯНИЯ НА ЭФФЕКТИВНОСТЬ ФАРМАЦИИ}

Вардомацкая
Людмила
Петровна
Лилюхин
Андрей
Михайлович

Вардомацкая

кандидат экономических наук, доцент, Ростовский государственный медицинский университет (344022, Россия, г. Ростов-на-Дону, пер. Нахичеванский, 29). E-mail: econandsociologyRostGMU@yandex.ru кандидат социологических наук, доцент, Ростовский государственный медицинский университет (344022, Россия, г. Ростов-на-Дону, пер. Нахичеванский, 29). E-mail: econandsociologyRostGMU@yandex.ru

\section{Аннотация}

Изучаются необходимость и возможность использования технологий цифровой экономики и инструментов их реализации в здравоохранении, в частности, фармации. Исследуются особенности использования в фармацевтической отрасли таких инструментов цифровой экономики, как блокчейн, большие данные, искусственный интеллект, интернет вещей. Изучение возможности применения технологий цифровой экономики и их инструментов позволяет сделать выводы о реальных перспективах уменьшения трудозатрат, снижения стоимости производства и доставки лекарственных средств, невозможности реализации на фармацевтическом рынке поддельных и контрафактных лекарственных средств.

Ключевые слова: цифровая экономика, экономические отношения цифровой экономики, социальная сфера, фармация, инструменты технологий цифровой экономики, блокчейн, большие данные, искусственный интеллект, интернет вещей.

Здравоохранение представляет собой одну из важнейших отраслей социальной сферы, способствующей обеспечению безопасности страны, росту её экономики, повышению качества жизни. К сфере здравоохранения в соответствии с функционально-институциональным признаком, определяющим тип медицинской организации, относятся фармацевтические предприятия, объединенные общим понятием «фармация» [1]. Основные виды деятельности фармации заключаются в изучении 